\title{
Economic Burden of Malaria: A National Disease
}

\author{
A. Sangamithra \\ Professor, Department of Economics, Bharathiar University, Coimbatore, Tamil Nadu, India \\ https://orcid.org/0000-0003-4761-8150
}

\section{OPEN ACCESS}

Manuscript ID:

ECO-2021-09023675

Volume: 9

Issue: 2

Month: March

Year: 2021

P-ISSN: 2319-961X

E-ISSN: 2582-0192

Received: 09.01.2021

Accepted: 12.02.2021

Published: 01.03.2021

Citation:

Sangamithra, A., and

S. Vishnu. "Economic

Burden of Malaria: A

National Disease." Shanlax

International Journal of

Economics, vol. 9, no. 2, 2021, pp. 26-30.

DOI:

https://doi.org/10.34293/

economics.v9i2.3675

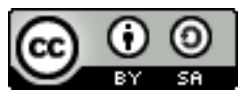

This work is licensed under a Creative Commons Attribution-ShareAlike 4.0 International License

\author{
S. Vishnu \\ Ph.D. Research Scholar, Department of Economics \\ Bharathiar University, Coimbatore, Tamil Nadu, India \\ https://orcid.org/0000-0001-9182-4758
}

\begin{abstract}
World Health Organization (WHO) stated that Malaria is a life-threatening parasite illness caused by the Genus Plasmodium spreading to human beings through the bites of infected female Anopheles mosquitoes. Malaria disease is curable and preventable. Unawareness of Malaria in non-endemic areas needs specific attention and the need for health awareness through the health care workers should be enhanced usual care in both areas. Despite being aware of the government programs and measures for the control of Malaria and the endless major problem of health disease in India and many other nations. The complexness and the panic preponderance of the disease are governed by multiple limitations as technological, functional, and monetary and therefore go on inflicting heavy socio-economic losses to people.
\end{abstract}

Keywords: Malaria, Records, Economics, Economic burden, Preventive measures

Malaria is a life-threatening parasite illness caused by the Genus Plasmodium spreading to human beings through the bites of infected female Anopheles mosquitoes. Malaria disease is curable and preventable (World Health Organization). Malaria symptoms are fever, headache, and body ache, rigor, chill, vomiting, and impossible to direct transmission from a Malaria-infected person to a healthy person. Malaria disease is classified into four types there are namely Plasmodium malaria, Plasmodium Vivax, Plasmodium Falciparum, and Plasmodium Ovale. Plasmodium Vivax malaria was highly affected in South Asia, particularly in India. In some cases, the parasites because Malaria enters the body but remains dormant for a long time. Infected Anopheles female mosquitoes carry the parasites flow into the bloodstream, once enter the body to travel to the liver and mature. After several days, the adult parasites enter the bloodstream and begin to infect red blood cells. Exacerbation of the disease can lead to jaundice, meningitis, and kidney damage.

\section{Malaria: Threatening Disease}

There were reported 229 million malaria vector cases in 2019 in 87 countries, reduce from 238 million in 2000. Malaria cases (i.e., cases per 1000 population at risk) decreased from 80 in 2000 to 58 in 2015 and 57 in 2019 world widely. Between 2000 to 2015, worldwide malaria cases declined by 27 percent, and between 2015 and 2019 it declined by less than or equal to 2 percent, at a low rate of decline worldwide widely, malaria died have reduced over the period 2000-2019, from 736000 in 2000 to 409000 in 2019.

\section{Introduction}


The percentage of total malaria death among children. Underage 5 years was 84 percent in 2000 and 67 percent in 2019. The global death of malaria vector diseases caused in 2015, the Global Technical Strategy baseline (GTS) was about 453000 (WHO Report 2020). Unawareness of malaria in non- endemic areas needs specific attention and the need for health awareness through the health care workers should be enhanced usual care in both areas. Despite being aware of the government programs and measures for the control of malaria.

Table 1: Indicators for Malaria in India (2001-2020)

\begin{tabular}{|c|c|c|c|c|c|c|c|c|c|}
\hline Year & $\begin{array}{c}\text { Population in } \\
\text { Thousand }\end{array}$ & $\begin{array}{c}\text { Blood smear } \\
\text { examined }\end{array}$ & $\begin{array}{c}\text { Positive } \\
\text { cases }\end{array}$ & (Pf Cases) & (ABER) & (API) & (SPR) & (SFR) & Deaths \\
\hline 2001 & 984579 & $90,389,019$ & $2,085,484$ & $1,005,236$ & 9.18 & 2.12 & 2.31 & 1.11 & 1005 \\
\hline 2002 & 1013942 & $91,617,725$ & $1,841,229$ & 897,446 & 9.04 & 1.82 & 2.01 & 0.98 & 973 \\
\hline 2003 & 1027157 & $99,136,143$ & $1,869,403$ & 857,101 & 9.65 & 1.82 & 1.89 & 0.86 & 1006 \\
\hline 2004 & 1040939 & $97,111,526$ & $1,915,363$ & 890,152 & 9.33 & 1.84 & 1.97 & 0.92 & 949 \\
\hline 2005 & 1082882 & $104,143,806$ & $1,816,569$ & 805,077 & 9.62 & 1.68 & 1.74 & 0.77 & 963 \\
\hline 2006 & 1072713 & $106,725,851$ & $1,785,129$ & 840,360 & 9.95 & 1.66 & 1.67 & 0.79 & 1707 \\
\hline 2007 & 1087582 & $94,928,090$ & $1,508,927$ & 741,076 & 8.73 & 1.39 & 1.59 & 0.78 & 1311 \\
\hline 2008 & 1119624 & $97,316,158$ & $1,526,210$ & 775,523 & 8.69 & 1.36 & 1.57 & 0.80 & 1055 \\
\hline 2009 & 1150113 & 103396076 & 1563,574 & 839,877 & 8.99 & 1.36 & 1.51 & 0.81 & 1144 \\
\hline 2010 & 1167360 & 10604023 & 1495817 & 779549 & 9.21 & 1.37 & 1.41 & 0.74 & 1018 \\
\hline 2011 & 1194901 & 109313294 & 1310656 & 665004 & 9.12 & 1.10 & 1.20 & 0.61 & 754 \\
\hline 2012 & 1211580 & 109048884 & 1067824 & 533695 & 9.00 & 0.88 & 0.98 & 0.49 & 519 \\
\hline 2013 & 1221640 & 113445106 & 881730 & 463846 & 9.26 & 0.72 & 0.78 & 0.41 & 440 \\
\hline 2014 & 1234995 & 124066331 & 1102205 & 722546 & 10.05 & 0.89 & 0.89 & 0.58 & 562 \\
\hline 2015 & 1265173 & 121141970 & 1169261 & 778821 & 9.58 & 0.92 & 0.97 & 0.64 & 384 \\
\hline 2016 & 1283303 & 124933348 & 1085823 & 711502 & 9.74 & 0.85 & 0.87 & 0.57 & 331 \\
\hline 2017 & 1315092 & 125977799 & 844558 & 529530 & 9.58 & 0.64 & 0.67 & 0.42 & 194 \\
\hline 2018 & 1337617 & 124475724 & 429928 & 207198 & 9.31 & 0.32 & 0.35 & 0.17 & 96 \\
\hline 2019 & 1349004 & 132752934 & 338513 & 156937 & 9.84 & 0.25 & 0.25 & 0.12 & 77 \\
\hline 2020 & 1337645 & 16376515 & 19980 & 15716 & 1.22 & 0.01 & 0.12 & 0.10 & 2 \\
\hline
\end{tabular}

PF: Plasmodium Falciparum; ABER: Annual Blood Examination Rate; API: Annual Parasite Incidence;

SPR: Slide positivity rate and SFR: Slide falciparum Rate

Source: National Vector Borne Disease Control Programme (nvbdcp.gov.in)

Figure 1: Indicators for Malaria in India (2001-2019)

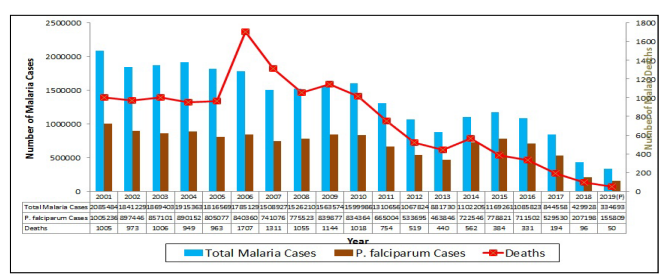

Source: National Vector Borne Disease Control Programme (nvbdcp.gov.in)

World Health Organization (WHO) report recorded East Asian region accounted for about
3 percent of the burden of malaria cases globally. Malaria cases reduced 73 percent in the region from 23 million in 2000 to about 6.3 million in 2019 and discovered. In India, the fight against malaria with reduction and prevention in case and death of 18 percent and 20 percent respectively over last two years and also recorded a decrease in the number of death from malaria last twenty years. Nearly 25 percent of the population has not received regular indoor residual insecticide spraying, highlighting the need for strengthening the national program (Suresh Balan et al., 2016). 
Table 2: Incidence of Malaria Rural and Urban Area of Tamil Nadu

\begin{tabular}{|c|c|c|c|c|c|c|}
\hline Years & State case & Rural case & $\begin{array}{c}\text { Chennai } \\
\text { case }\end{array}$ & $\begin{array}{c}\text { Chennai } \\
\text { percent }\end{array}$ & $\begin{array}{c}\text { Other Urban } \\
\text { Cases }\end{array}$ & $\begin{array}{c}\text { Other Urban } \\
\text { Percent }\end{array}$ \\
\hline 2010 & 17086 & 6031 & 9789 & 57.20 & 1266 & 12.90 \\
\hline 2011 & 22171 & 6602 & 14927 & 67.30 & 642 & 4.30 \\
\hline 2012 & 18869 & 7146 & 11090 & 58.80 & 633 & 3.40 \\
\hline 2013 & 15081 & 5893 & 8537 & 56.60 & 651 & 4.30 \\
\hline 2014 & 8729 & 3708 & 4669 & 53.50 & 352 & 4.00 \\
\hline 2015 & 5587 & 2045 & 3338 & 59.75 & 204 & 3.60 \\
\hline 2016 & 4340 & 1409 & 2743 & 62.40 & 224 & 5.20 \\
\hline 2017 & 5449 & 1360 & 3895 & 71.5 & 194 & 3.6 \\
\hline 2018 & 3758 & 806 & 2823 & 75.1 & 129 & 3.4 \\
\hline 2019 till June & 583 & 254 & 448 & 61.2 & 30 & 3.9 \\
\hline
\end{tabular}

Source: tnhealth.org.in

Malaria incidence rural and urban area of Tamil Nadu 2010-2019 till June malaria cases recorded yearly declining positive economic scale. The urban area in Chennai with a high population of slum people is affected by malaria diseases more than the other urban in Tamil Nadu. Malaria peak years in Tamil Nadu recorded from 2010 to 2012 then after slow down the disease most of the cases all over the Tamil Nadu. As per the Integrated Disease Surveillance Programmes of the National Center for Disease Control, the most number of cases was recorded in Chennai, Tiruvallur, Dharmapuri, Madurai and Viruthunagar, districts.

\section{Economic Impact of Malaria Diseases in India}

Information on the economic responsibility of malaria can help to target the interventions efficiently and equitably and to rationalize investment in exploration and custody. Such data can notify our knowledge of the economic and period burdens of disease episodes, the determined migrants, treatment-seeking behavior, and the differential economic impact on community subgroups. Surveys are conventional wisdom all classified as macroeconomic or microeconomic studies. Macroeconomic studies are concerned with the impact at the level of the whole economizing. Apart from Barlow's seminal work publicized in 1967, this area of research has been disregarded until very newly, when two investigations have used malaria as an illustrative variable in economic growth models using cross-country regression analysis, and have demonstrated a meaningful relationship between improvement in the gross domestic product (GDP) per capita and the burden of malaria. Microeconomic studies are concerned with impact at the level of an efficient unit, such as the household or company. A widespread method of analysis employed in many studies has been to sum the explicit costs of expenditure on deterrence and medication and the indirect costs of productive labor.

More than 90 percent of India's population resides in the malaria alert area. According to national sources, 80 percent of malaria reported in the country is confined space to population residing in the forest. Rural difficult and inaccessible areas using a nationally representative sample the study has estimated the economic burden of malaria in India by applying the cost of illness approach using the information on cost of treatment day cost and earnings foregone from the national sample survey data a sensitivity exploring was carried out by presenting two alternative scenarios of deaths. The results indicate that the total economic burden of malaria in India could be around US dollar 1940 million. The major Economic burden comes from lost earnings 75 percent, while 24 percent comes from treatment costs. Mortality rate decreasing as a report of the past count. In the analysis pattern in public expenditure by the national vector-borne diseases control program (NVBDCP) visible a declining focus of the central government on vector-borne diseases among states does not reflect the burden of malaria, the major vector-borne diseases (Indrani 
Gupta and Samik Chowdhary-2014). Vector-Borne Diseases Control Programme (NVBDCP) stated that malaria and other bone in India last few years' death rates gradually declining.

\section{Malaria: Preventive Measures}

Elimination of mosquito breeding suggesting mainly proper sealing of overhead tanks, wells and covering all water containers preventing mosquitoes from laying eggs and thereby preventing the mosquitoes breeding. Un-treated Plasmodium falciparum may cause leading to death. At the beginning diagnosis of Malaria fever and taking complete proper treatment will prevent transmission of malaria parasites - mosquitoes breeding source reduction. Anti-adult measures by spray frequently use to operate Malaria-affected areas. Malaria prevention programs conduct frequently and advertise promotions. Environmental factors are mainly responsible for increasing the cases and awareness programs, and preventive measures have helped to decline the cases. Take protective measures to reduce contact with mosquitoes, especially during the day and night. The habit of Anopheles mosquitoes and measures include remaining in well-screened areas using mosquito nets and put on clothes that cover the fullest of the body.

\section{Conclusion}

While the exaggerated priority in this paper is on the economic burden and consequences of malaria. The negative impact of malaria on their fore elasticity extends the financial and socio-economic cost to the family and community. The economic cost of the disease may contribute surplus returns to measurement and evaluation of the economic merits of disease prevents control programs. However, the malaria story is infinity. People have our brand of resilience, innovation, and tricks for survival. The economic burden of malaria is more than the socioeconomically weak people as compared to rich people in both the study areas which were associated with unhealthy living situations and poor level of schooling. Moreover, the modification of health services is also a requirement for the poor and needy population. Effective health education in schools on preventative measures against malaria, which may diminish its incidence and help to attain a sharp decrease in its economic burden.

\section{References}

Attanayake, N, et al. "Household Costs of 'Malaria' Morbidity: A Study in Matale District, Sri Lanka." Tropical Medicine \& International Health: $T M \& I H$, vol. 5, 2000, pp. 595-606.

Berthelemy, Jean-Claude, and Josselin Thuilliez. "The Economics of Malaria in Africa." WIDER Working Paper 2014/047, 2014.

Deressa, Wakgari, et al. "Malaria-related Health Seeking Behaviour and Challenges for Care Providers in Rural Ethiopia: Implications for Control." Journal of biosocial science, vol. 40, 2005, pp. 115-135.

Dhingara, Neeraj, et al. "Adult and Child Malaria Mortality in India: A Nationally Representative Mortality Survey." The Lancet, vol. 376, 2010, pp. 1768-1774.

Gallup, John Luke, and Jeffrey D. Sachs. "The Economic Burden and Malaria." The American Journal of Tropical Medicine and Hygiene, vol. 64, 2001, pp. 85-96.

Goodman, Catherine, et al. Economic Analysis of Malaria Control in Sub-Saharan Africa. Global Forum for Health Research, 2000.

Guidelines on Mosquito and Other Vector Control Response. Ministry of Health and Family Welfare, Government of India, 2020.

Gupta, Indrani, and Samik Chowdhury. "Economic Burden of Malaria in India: The Need for Effective Spending." Policy and Practice, vol. 3, no. 1, 2014, 95-102.

Hansan, Kara, et al. The Economics of Malaria Control Interventions. World Health Organisation, 2004.

Kumari, Amritha, et al. "Estimating the Economic Burden of Malaria and Assessing Its Relationship with Socio-Economic Condition in Rohtak and Mewat Districts of Hariyana, India." British Journal of Medicine and Medical Research, vol. 7, no. 8, 2015, pp. 654-661.

Malaney, Pia. "Micro-Economics Approaches to Evaluating the Burden of Malaria." CID Faculty Working Paper No.99, 2003. 
Mazumdar, S. "Prevalence, Risk Factors and Treatment-seeking Behaviour for Malaria: The Results of a Case Study from the Terai Region of West Bengal, India." Annals of Tropical Medicine and Parasitology, vol. 105, 2011, pp. 197-208.

Meremikwu, Martin, et al. "Malaria in Women and Children." Maternal and Child Health: Global Challenges, Programs, and Policies, 2009, pp. 205-223.

Moreno-Gutierrez, Diamantina, et al. "Economic Costs Analysis of Uncomplicated Malaria case Management in the Peruvian Amazon." Malaria Journal, vol. 19, 2020.

Mukherjee, Sujata. "Environmental Thoughts and Malaria in Colonial Bengal: A Study in Social Response." Economic and Political Weekly, vol. 43, no. 12/13, 2008, pp. 54-61.

National Framework for Malaria Elimination in India, 2016-2030. Ministry of Health and Family Welfare, Government of India, 2020.

Pavuluri, Prudhvi. "Analysis of Malaria Situation in Chattisgarh: Issues, Strategies and Solutions from a Field Workers Perspective." Amity Journal of Healthcare Management, vol. 2, no. 2, 2017, pp. 13-20.
Sangamithra, A., and P. Arunkumar. "A Study on the Determinants of Expenditure Incurred for Agricultural Workers for Illness Related to Health Hazards in Theni District, Tamil Nadu." Shanlax International Journal of Economics, vol. 7, no. 2, 2019, pp. 27-33.

Shihorva, Viera, et al. "Costs Analysis of the Treatment of Imported Malaria." Malaria Journal, vol. 11, 2012.

Shretta, Rima, et al. "Malaria Elimination Transmission and Costing in the Asia-Pacific: Developing an Investing Case." Wellcome Open Research, vol. 4, 2019.

Singh, Abha Lakshmi, and Atiqur Rahman. "Malaria and related Environmental Issues in India: A Case Study of Aligarh City." GeoJournal, 2001, pp. 89-99.

Sonkong, Krit, et al. "Treatment Seeking Behaviour and Prevalence of Treatment Delay among Malaria Patients along Thailand-Myanmar Border in Tak Province." Asian Pacific Journal of Tropical Disease, vol. 5, no. 4, 2015, pp. 279-283.

http://www.tnhealth.org/dphfacts/malaria.htm

\section{Author Details}

Dr. A. Sangamithra, Professor, Department of Economics, Bharathiar University, Coimbatore, Tamil Nadu, India, Email ID: a.sangamithra@gmail.com

S. Vishnu, Ph.D. Research Scholar, Department of Economics, Bharathiar University, Coimbatore, Tamil Nadu, India, Email ID: vsssss572@gmail.com 